\title{
PUBLIC HEALTH ASSOCIATION OF AUSTRALIA CONFERENCES
}

\section{3}

\section{SECOND PHAA INCARCERATION CONFERENCE}

\section{Human Rights, Human Wrongs, Human Costs:}

The health of prisoners and detainees in Australia in the 21st century

2-3 April 2003

Mercure Hotel, Brisbane

The health of incarcerated populations is often regarded as separate from, or unrelated to, the health of the general community. However, the reality is that the majority of incarcerated people return to the wider community after relatively short periods of time. Therefore, health gains for incarcerated individuals are health gains for us all, while missed opportunities for those incarcerated adversely affect us all. Health and other issues pertaining to incarceration have a significant affect on families, community health, political decisions, social policy, and ethical and moral deliberations. The diversity of incarcerated populations, such as adult prisons, youth detention centres, police watch houses, and immigration detention facilities, gives rise to special challenges in addressing the range of health needs among incarcerated groups. This conference will provide a forum for review and analysis of these important issues, as well as making recommendations for the way forward.

\section{Conference sub-themes}

Communicable diseases, alcohol and other drugs, mental health, healthy prisons, women's health, post release and family issues, Aboriginal and Torres Strait Islander issues, violence and injury, staff issues for clinical staff and custodial staff, and research.

\section{THIRTY-FIFTH PHAA ANNUAL CONFERENCE}

\section{Essentials, Differentials, and Potentials in Health}

28 September-1 October 2003

Brisbane Convention and Exhibition Centre, Brisbane

The three components of the Thirty-Fifth PHAA Annual Conference reflect important aspects of contemporary public health research and practice:

- Essentials - The essential disciplines required to research and conduct public health, as well as the essential requirements for the promotion and maintenance of health and wellbeing;

- Differentials - Understanding the differences in health status and associated causal factors, as well as appreciating how the variety of public health interventions can ameliorate differences in health need;

- Potentials - Visions for the future. What can we take from our present understandings to improve public health knowledge and practice into the future?

\section{Conference sub-themes}

Injury and indigenous health, social policy and social determinants of health, tobacco and health, chronic disease: risk factors beyond behaviour change, engaging the community in health policy, health equity, and sustainable environments.

\section{4}

\section{IMMUNISATION CONFERENCE}

The 9th National Public Health Association of Australia's Immunisation Conference is to be held in Cairns, Far North Queensland, in late 2004.

Planning is underway to include issues from our Asian Pacific region with a focus on China, South East Asia and the Western Pacific.

Further information about these conferences can be obtained by visiting the Public Health Association of Australia website at www.phaa.net.au/conferences/frame_conferences or by contacting the PHAA Secretariat by email conference@phaa.net.au or by telephone (02) 62852373. 